\title{
Retinal Vessel Responses to Passive Tilting
}

\author{
R. M. BAER* and D. W. HILL $\dagger$ \\ London
}

\begin{abstract}
Summary
Alterations in retinal vessel calibre on changing posture may indicate an autoregulatory response to changing perfusion pressure. The effect of passive tilting on retinal response in healthy individuals was investigated. Subjects were supported on a specially constructed tilting table. The control measurements were taken with the body in a $30^{\circ}$ head up position. Red-free fundus photographs were taken before, during and after a three minute period of $30^{\circ}$ head down tilting. Ten subjects were assessed (mean age 29 years: range 18-38). A total of 92 arteriolar and 86 venular sites were measured. On tilting to the head down position arterioles showed an early and significant decrease in calibre: mean $-3.1 \%(p<0.001)$. Venules showed an increase of $3.7 \%(\mathbf{p}<0.001)$. The response was not sustained throughout the period of tilting despite a maintained increase in ocular perfusion pressure, which was estimated in six of the subjects.
\end{abstract}

The circulation of the retina is autoregulated so that a constant blood flow is maintained despite changes in the ocular perfusion pressure. ${ }^{1,2}$ The mechanisms underlying this process are not well understood. Alterations in ocular perfusion pressure can be obtained experimentally by simple changes in posture, ${ }^{3}$ e.g. lying to standing. However, the major haemodynamic change associated with a change in posture is a redistribution of the venous volume. ${ }^{4}$ This varies considerably with the degree of skeletal muscle activity in the legs on standing and is a difficult factor to control. To alleviate this additional variable the subject can be passively tilted on a specially constructed tilting table which eliminates the need for muscular effort. When the eye is below the level of the heart the ophthalmic artery pressure and intraocular pressure both increase.$^{5-8}$ The rise in IOP is proportionately smaller so there is a net increase in ocular per- fusion pressure. If the retinal blood flow is to remain constant the retinal arterioles must constrict.

\section{Materials and Methods}

Ten healthy subjects (mean age 28.9; range 18-31; seven males and three females) volunteered to participate in the study following informed consent. None of the subjects had any history of respiratory, cardiovascular or ophthalmic disease.

The subjects were supported on a specially constructed tilting table lying on their lefthand side in the $30^{\circ}$ head up position. The table was constructed so that the axis around which it rotated would be as close as possible to the axis of the eye under investigation, in order to minimise movements of the camera. The left pupil was dilated using G. Tropicamide $1 \%$. The blood pressure and pulse were recorded from the right upper arm using an

\footnotetext{
*Smith and Nephew Fellow.

$\nmid$ Research Professor in Ophthalmology, Royal College of Surgeons. Consultant Ophthalmologist, Moorfields Eye Hospital, London.

Correspondence to: Mr R. Baer FRCS FCOphth, Moorfields Eye Hospital, London EC1V 2PD.
} 
Table I Variation in retinal vessel calibre during early head down tilt in 10 normal subjects (mean \pm SEM)

\begin{tabular}{cccccc}
\hline Subject & $\begin{array}{c}\text { Variation in } \\
\text { arteriole } \\
\text { calibre } \%\end{array}$ & Sig. & $\begin{array}{c}\text { Variation in } \\
\text { venule } \\
\text { calibre } \%\end{array}$ & Sig. & $\begin{array}{c}\text { Estimated rise } \\
\text { in perfusion } \\
\text { pressure } \%\end{array}$ \\
\hline NC & $-8.75 \pm 1.37$ & $\mathrm{P}<0.001$ & $-3.18 \pm 2.41$ & $\mathrm{NS}$ & 40.4 \\
RP & $-0.34 \pm 0.71$ & $\mathrm{NS}$ & $6.96 \pm 1.99$ & $\mathrm{P}<0.01$ & 3.4 \\
KL & $-8.16 \pm 2.88$ & $\mathrm{P}<0.05$ & $1.44 \pm 1.47$ & $\mathrm{NS}$ & 31.9 \\
SD & $-1.02 \pm 0.74$ & $\mathrm{NS}$ & $7.80 \pm 3.21$ & $\mathrm{NS}$ & 20.0 \\
AB & $-4.70 \pm 0.79$ & $\mathrm{P}<0.001$ & $3.32 \pm 1.70$ & $\mathrm{NS}$ & 27.8 \\
KB & $+0.03 \pm 1.22$ & $\mathrm{NS}$ & $4.62 \pm 1.74$ & $\mathrm{P}<0.05$ & 11.6 \\
NR & $-2.88 \pm 0.35$ & $\mathrm{P}<0.001$ & $7.78 \pm 1.45$ & $\mathrm{P}<0.001$ & \\
CD & $-4.20 \pm 1.09$ & $\mathrm{P}<0.005$ & $0.94 \pm 1.59$ & $\mathrm{NS}$ & \\
AE & $-1.67 \pm 0.59$ & $\mathrm{P}<0.05$ & $4.97 \pm 1.36$ & $\mathrm{P}<0.001$ & \\
PG & $-1.76 \pm 1.13$ & $\mathrm{NS}$ & $5.33 \pm 0.98$ & $\mathrm{P}<0.001$ & \\
\hline
\end{tabular}

NS = not significant

automatic sphygmomanometer (COPAL-UA 231). Measurements were recorded until they were seen to have stabilised and the subjects then underwent a 'trial run' of head down tilting to both familiarise them with the technique and to try and eliminate any anxieties that might interfere when the procedure was carried out with photographs being taken. The subjects were then returned to the $30^{\circ}$ head up position and a further period of cardiovascular stabilisation ensued. When the $\mathrm{BP}$ and pulse were stable the first phase of baseline retinal photographs were taken. These were all recorded by the same observer using a wide angle Canon camera (CF 60-S). The camera shutter was triggered during the diastolic phase of the pulse. A series of five photographs were taken in rapid succession at each phase of the experiment. The subjects were then rapidly tilted to the $30^{\circ}$ head down position and this was maintained for a period of three minutes. BP measurements were commenced at $0.5,1.5$ and 2.5 minutes (the machine has a delay of approximately 30 seconds before the diastolic measurement is recorded). Two sets of photographs were taken at 1.5 minutes and just prior to the end of the three minute period. On completion of this last set of photographs the subjects were returned to the $30^{\circ}$ head up position and a further set were taken as well as a BP reading. Finally these were repeated 1.5 minutes after regaining the head up position.

On another occasion the procedure was repeated to obtain IOP measurements in six of the subjects. This was done using a Goldmann applanation tonometer mounted on a Haag-Streit slit-lamp. The slit-lamp was at right angles to its normal position on the supporting table.

All photographs were taken with Ilford FP4 film using a red-free filter and developed with

Table II Variation in retinal vessel calibre during late head down tilt in 10 normal subjects (mean $\pm S E M)$

\begin{tabular}{cccccc}
\hline & $\begin{array}{c}\text { Variation in } \\
\text { arteriole } \\
\text { calibre } \%\end{array}$ & Sig. & $\begin{array}{c}\text { Variation in } \\
\text { venule } \\
\text { calibre } \%\end{array}$ & Sig. & $\begin{array}{c}\text { Estimated rise } \\
\text { in perfusion } \\
\text { pressure } \%\end{array}$ \\
\hline NC & $-11.2 \pm 2.3$ & $\mathrm{p}<0.002$ & $-6.82 \pm 2.84$ & $\mathrm{p}<0.05$ & 25.0 \\
RP & $1.47 \pm 0.95$ & $\mathrm{NS}$ & $3.53 \pm 1.27$ & $\mathrm{p}<0.05$ & 15.3 \\
KL & $-3.70 \pm 1.43$ & $\mathrm{p}<0.05$ & $-5.02 \pm 3.11$ & $\mathrm{NS}$ & 48.9 \\
SD & $0.43 \pm 1.08$ & $\mathrm{NS}$ & $10.18 \pm 2.17$ & $\mathrm{p}<0.01$ & 36.9 \\
$\mathrm{AB}$ & $2.04 \pm 2.18$ & $\mathrm{NS}$ & $6.35 \pm 1.62$ & $\mathrm{p}<0.05$ & 22.2 \\
$\mathrm{~KB}$ & $6.82 \pm 2.32$ & $\mathrm{p}<0.02$ & $4.25 \pm 2.43$ & $\mathrm{NS}$ & 41.9 \\
$\mathrm{NR}$ & $0.03 \pm 0.77$ & $\mathrm{NS}$ & $2.34 \pm 2.54$ & $\mathrm{NS}$ & $\mathrm{NS}$ \\
$\mathrm{CD}$ & $-4.60 \pm 1.13$ & $\mathrm{p}<0.005$ & $-1.97 \pm 1.50$ & $\mathrm{NS}$ & \\
$\mathrm{AE}$ & $0.01 \pm 1.46$ & $\mathrm{NS}$ & $6.86 \pm 1.74$ & $\mathrm{p}<0.01$ & $\mathrm{NS}$ \\
$\mathrm{PG}$ & $-1.07 \pm 0.91$ & $\mathrm{NS}$ & $0.06 \pm 1.34$ & & \\
\hline
\end{tabular}

NS $=$ not significant 


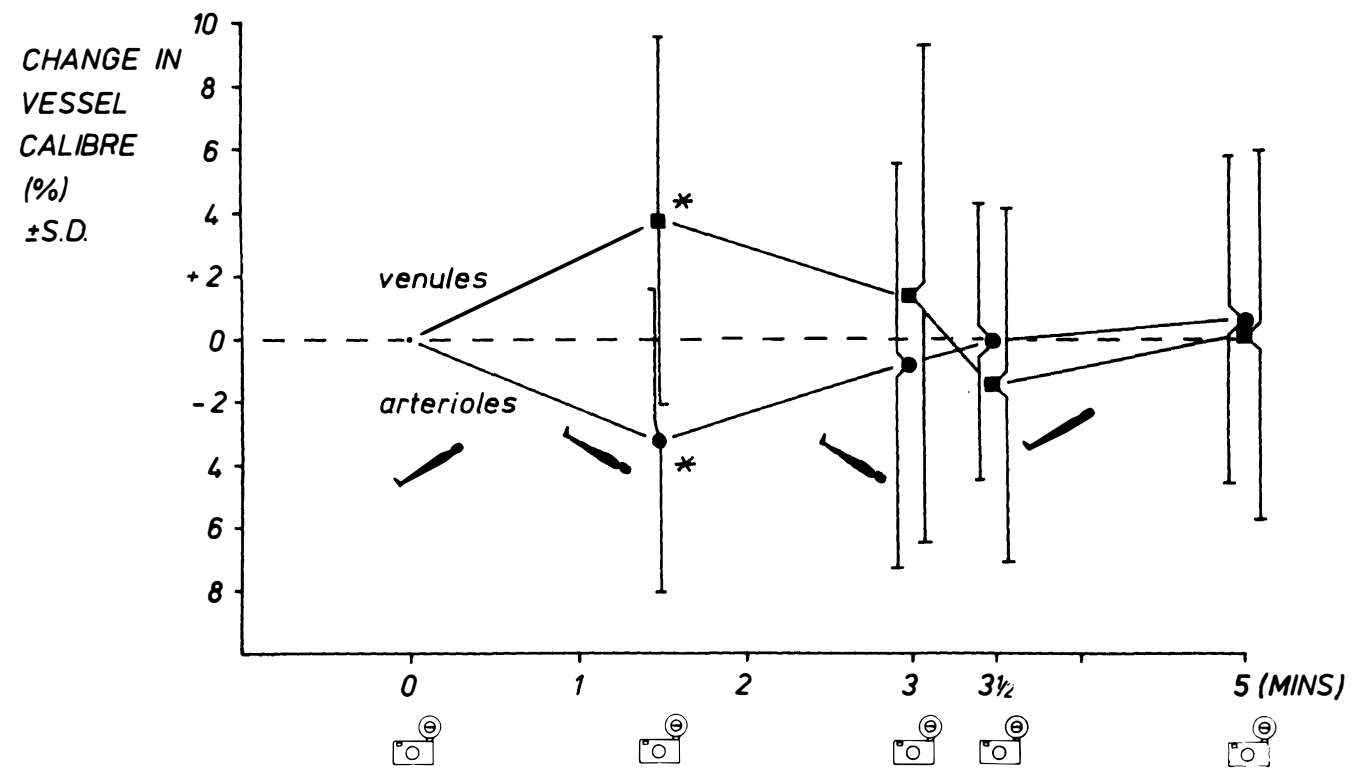

Significantly different $(p<0.001)$ from pre-inversion

Fig. 1. Mean \% calibre changes for all subjects.

sensitometric control. The films were ana- timet 800 Image Analyser. ${ }^{9}$ Each subject had lysed using the Cambridge Instruments Quan- 18 vessel widths analysed. Equal numbers of

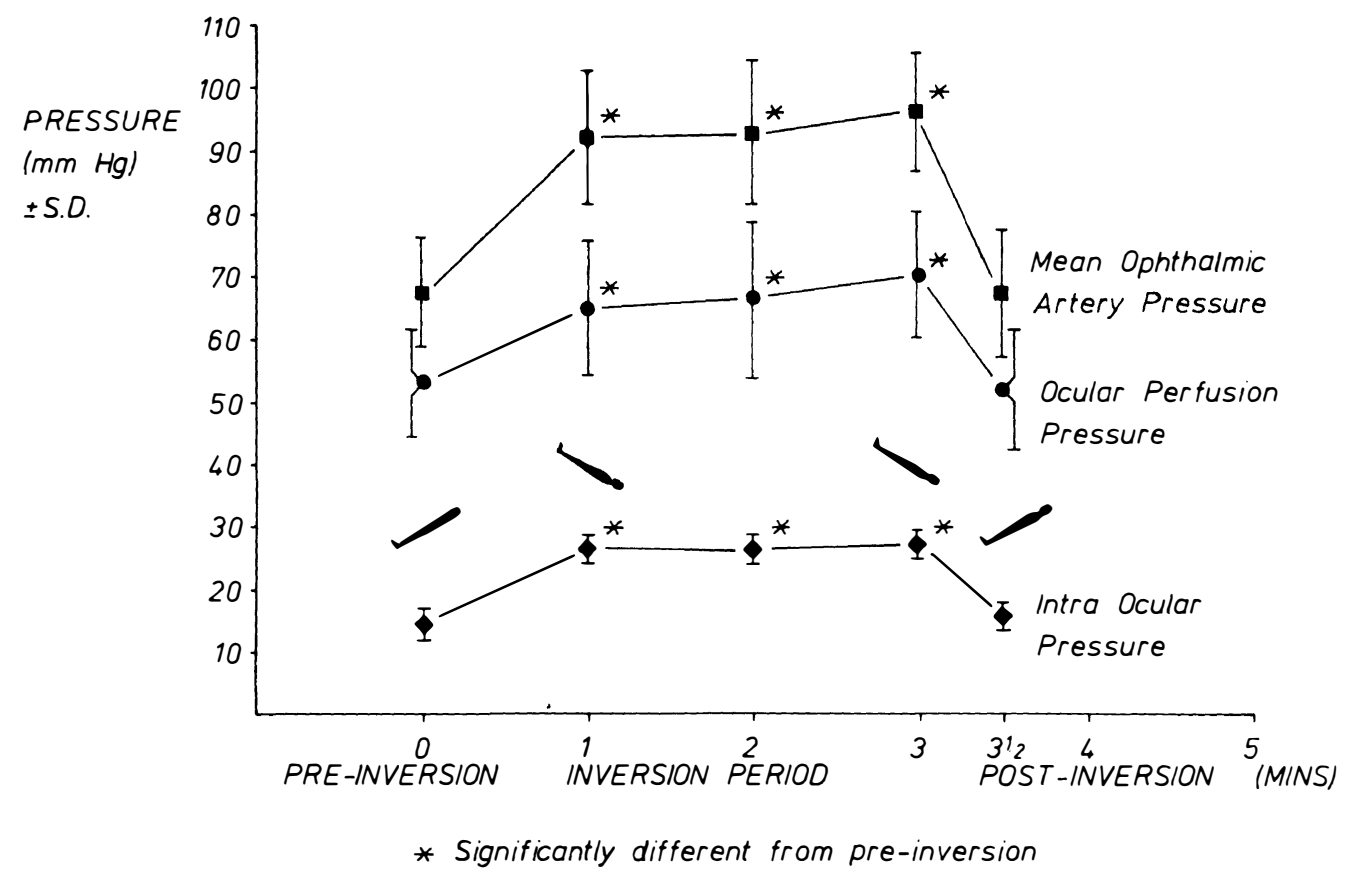

Fig. 2. Mean IOP in six subjects (see Tables I and II) together with derived mean ophthalmic artery and ocular perfusion pressures. 


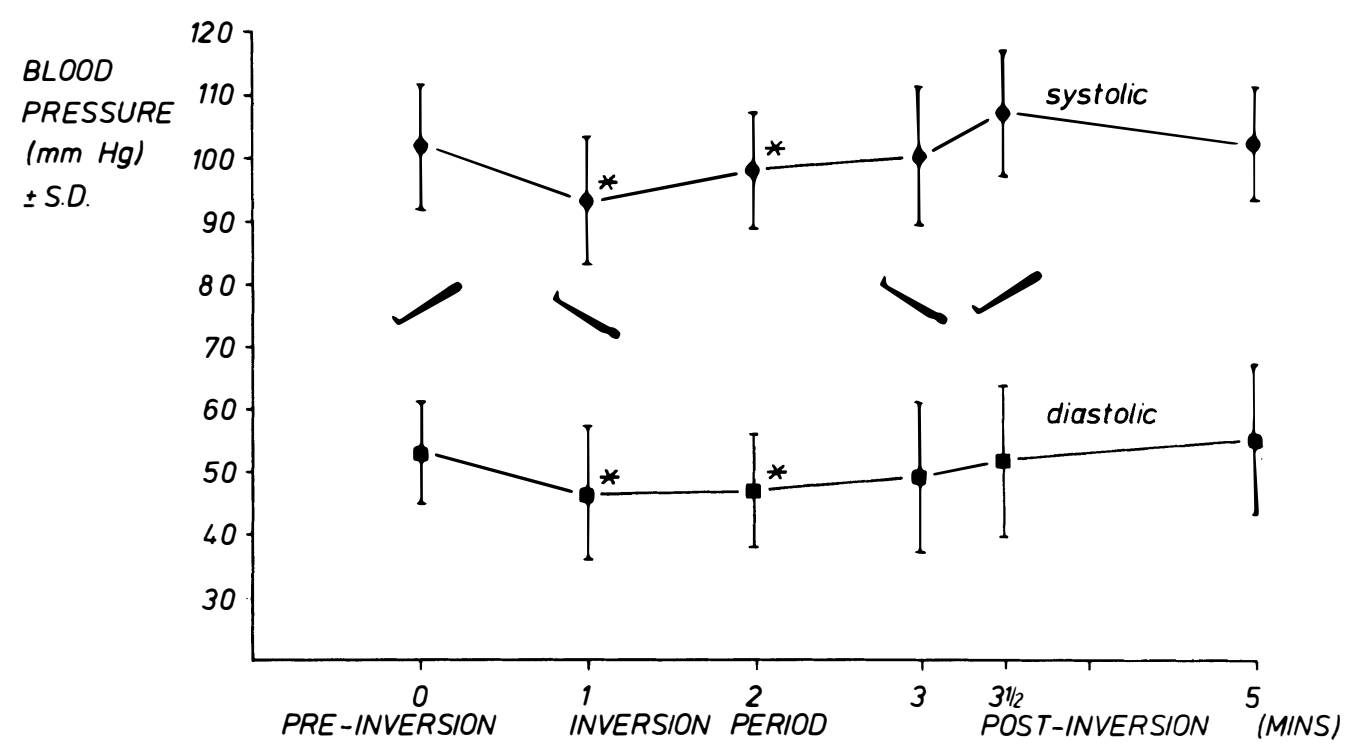

* Significantly different $(p<0.01)$ from pre-inversion

Fig. 3. Mean brachial artery pressure for all subjects.

arterioles and venules were chosen where possible. Vessel calibres at these sites were measured and the means, standard errors of the means, and one way analysis of variance for each site within the replications and between the phases, were calculated using a specially designed software programme. The percentage change in the calibre for each vessel was calculated as it varied throughout the experiment, taking the baseline reading as the control.

Ocular perfusion pressure was estimated in the six subjects whose IOP measurements were available. Ocular perfusion pressure is obtained from the formula:

OPP $=$ Mean ophthalmic artery pressure minus IOP. Mean ophthalmic artery pressure could be estimated from the mean brachial artery pressure if the difference in vertical height between the arm and eye was taken into account ${ }^{10}$ (each $\mathrm{cm}$ of blood exerts $0.735 \mathrm{mmHg}$ pressure).

\section{Results}

A total of 92 arteriolar and 86 venular sites were measured. Tables I and II show the individual variation in retinal vessel calibre for each subject in early and late head down tilting respectively.
On early head down tilting the overall arteriolar calibre of all 10 subjects (mean \pm SD) decreased by $3.1 \% \pm 4.39(\mathrm{p}<0.001)$ (Fig. 1). Late head down tilting showed a maintained but smaller constriction which was not significantly different from the head up measurements of $0.8 \% \pm 6.47$.

On early head down tilting the venules increased in calibre by $3.7 \% \pm 5.9(\mathrm{p}<0.001)$ Fig. 1. As with the arteriolar response this became smaller in magnitude and not significantly different from the head up position by the end of the tilt: $1.3 \% \pm 7.94$. Intraocular pressure was also measured in six of the subjects. IOP (mean \pm SD mmHg) (Fig. 2). In the head up position was $14.2 \pm 2.0$ and increased to $26.7 \pm 1.0$ as soon as the head down position was reached. This is an increase of $12.5 \pm 2.2$ and is highly significant $(\mathrm{p}<0.001)$. This increase in IOP was maintained and did not vary significantly during the period of tilting. Ocular perfusion pressure was calculated for six of the subjects. In the head up position it was (mean \pm SD $\mathrm{mmHg}) 53 \pm 8.0$ and increased to $65 \pm 10.6$ on early head down tilting (Fig. 2). This is an increase of $22.6 \%$ and was significant $(p<0.001)$. The increase was maintained throughout the period of tilting and actually 
increased slightly towards the end of the three minutes. Brachial artery systolic and diastolic blood pressures showed a small but significant decrease on early head down tilting (Figure 3). This drop was not sustained during the period of head down tilting and by the end of the tilt there was no significant difference between the measurements recorded and the pre tilting. levels. Heart rate was recorded but remained remarkably stable during the procedure and the measurements are not therefore reported.

\section{Discussion}

This study has demonstrated a constriction of the measurable retinal arterioles in the initial stage of head down tilt combined with venous dilatation. This was accompanied by a rise in estimated ocular perfusion pressure, which can be explained on hydrostatic grounds, due to the rise in BP at the dependent head and a smaller rise in IOP. The rise in intraocular pressure on head down tilting is a well recognised phenomenon ${ }^{5-7}$ and over short periods of inversion is readily explained by reference to the laws of hydrostatics. The IOP has been observed to vary with the sine of the angle that the body makes with the horizontal. ${ }^{10}$ On complete inversion the IOP doubles. ${ }^{5}$ Our study would appear to have exaggerated this response since the degree of tilting was only $30^{\circ}$ head down and yet a $90 \%$ increase was observed. Unfortunately it was only recordable in six of the subjects due to technical difficulties imposed by the method and it is possible that the results are in some way unrepresentative. The rapid increase in IOP on inversion is almost certainly due to the rapid filling of the choroidal arteries and veins and the compressive effect that this has on the intraocular contents. The absence of valves in the orbital veins is an additional factor. ${ }^{7}$ Since $70 \%$ of the increase is observed during the first 10 seconds $^{6}$ it is not feasible to apportion any of this rise to an increase in the aqueous production or an outflow obstruction. Episcleral venous pressure undoubtedly rises on inversion and this must certainly play a role if the inverted posture were to be maintained for any period.

Towards the end of the three minute period the arteriolar constriction diminishes as does venous dilatation. In only two subjects NC and $\mathrm{CD}$ were significant arteriolar constrictions in the early phase of head down tilting followed by significant and maintained arteriolar constriction at three minutes. In addition only one NC had an estimated figure for the ocular perfusion pressure. This complex response in which the vessels appear to be normalising to their pre tilting calibres in the face of a maintained level of ocular perfusion pressure cannot be explained solely as autoregulatory. Further, in accord with the Poiseuille equation, ${ }^{11}$ the mean rise of perfusion pressure $22.6 \%$ would predict only the fourth root response in retinal arteriolar calibre: $2.2 \%$. This is less than the observed constriction of $3.1 \%$. It is possible that the initial venous distension provokes a rise in capillary pressure and further arteriolar constriction. A further analysis would require concomitant flow measurements, not available in this study.

We are grateful to Alan Crabtree for taking the photographs and John Houseman for constructing the table.

Mr Baer was supported by the Smith and Nephew Trustees. The project was supported by the Locally Arranged Research Fund at Moorfields.

\section{References}

${ }^{1}$ Riva CE, Sinclair SH, Grunwald JE: Autoregulation of the retinal circulation in response to decrease in perfusion pressure. Invest Ophthalmol Vis Sci 1981, 21: 43-8.

${ }^{2}$ Riva CE, Grunwald JE, Petrig BL: Autoregulation of human retinal blood flow. An investigation with laser doppler velocimetry. Invest Ophthalmol Vis Sci 1986, 27: 1706-12.

${ }^{3}$ Hague $S$ and Hill DW: Postural changes in perfusion pressure and retinal arteriolar calibre. $\mathrm{BrJOph}$ thalmol 1988, 72: 253-7.

${ }^{4}$ Blomqvist CG and Stone HL: Cardiovascular adjustments to gravitational stress. In: Handbook of Physiology. Volume III Part 2, Chapter 28. American Physiological Society, Maryland.

${ }^{5}$ Weinreb RN, Cook J, Friberg TR: Effect of inverted body position on intraocular pressure. Am JOphthalmol 1984, 98: 784.

${ }^{6}$ Friberg TR and Weinreb RN: Ocular manifestations of gravity inversion. J Am Med Assn 1985, 253: 1755.

${ }^{7}$ Friberg TR, Sanborn G, Weinreb RN: Intraocular and episceral venous pressure increase-during inverted posture. Am J Ophthalmol 1987, 103: 523-6.

${ }^{8}$ Zito M: Effects of two gravity inversion methods on 
heart rate, systolic brachial pressure and ophthalmic artery pressure. Physical Therapy 1988, 68: 20-25.

${ }^{9}$ Hill DW and Crabtree A: Vascular calibres. Trans Ophthalmol Soc UK. 1984, 104: 107.
${ }^{10}$ Kothe AC and Lovasik JV: Neural effects of body inversion: photopic oscillatory potentials. Curr Eye Res 1988, 7: 1221-9.

${ }^{11}$ Feke GT et al: Blood flow in the normal human retina. Invest Ophthalmol Vis Sci 1989, 30: 58-69. 